Ethics in Progress Quarterly • ethicsinprogress.org • Volume 2 (2011) • Issue 2 • pp. 141-150

News \& Reports

\title{
Konstanz Method of Dilemma Discussion (KMDD) by Prof. Georg Lind
}

\author{
Marta Szopka \& Filip Bardziński (Poznań, Poland)
}

Every man wishes to be good - this seemingly obvious statement may be an explanation of why does the interest in teaching ethics grow so rapidly. The demand for well-educated teachers, conscious of how important their task is, increases certainly in Poland. This is why professor Ewa Nowak, head of the Chair of Ethics in the Philosophy Institute of Adam Mickiewicz University (Poznan), along with her Ph.D. students, offered in Poznan on 6th - 10th February, 2012 a seminar-workshop led by professor Georg Lind, German psychologist and philosopher, author of the Konstanz Method of Dilemma Discussion (KMDD). The Konstanz Method, based on the Lawrence Kohlberg experiences, may be perceived as an innovatory way of fostering moral and democratic competencies with children and adolescents.

Most people throughout the world believe in democratic ideals. In democratic societies problems are being solved by a discourse free of violence, in which neither aggression nor appealing to authority play a dominant role. A moral judgement competence and discourse competence belong together in democratic citizens who express and exchange different opinions. Lawrence Kohlberg defined a moral competence as the capability to make moral judgements and decide accordingly to one's personal beliefs. Jürgen Habermas broadened the aforementioned definition with the theory of communicative action - Habermas insists that the democratic discourse should be free from violence and use of physical force (Lind, 2008a). In order to measure moral orientations and competences, Lind developed the Moral Judgement Test, in which the participant is confronted with two stories, which may inflict a moral dilemma. Its task is to judge whether a decision made by the hero of the story was right or wrong, and to 
evaluate a series of arguments in favour and opposing this decision, too. Research findings demonstrate that people agree with arguments supporting their own moral decision on a given problem, while rejecting arguments which disagree with their own opinion.

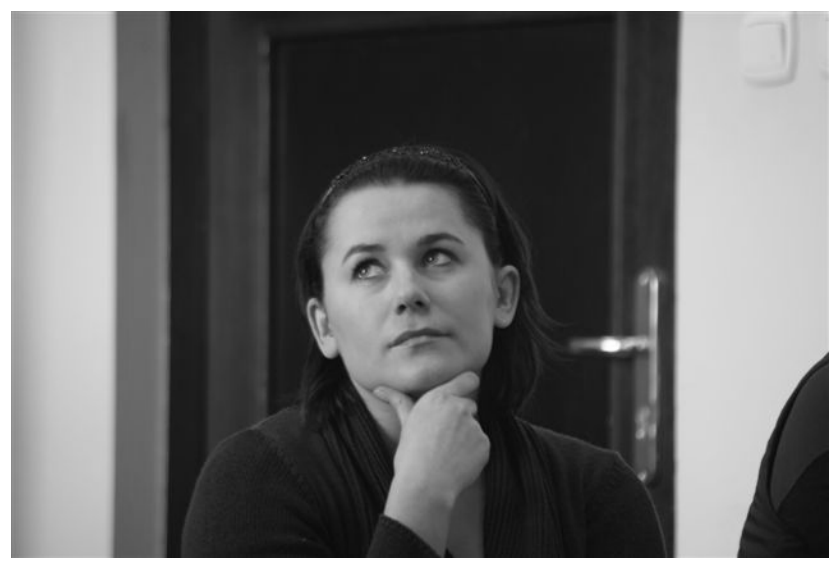

\section{Reflecting on moral issues}

Unfortunately, schools do not develop neither moral competencies nor discourse competencies in students. Traditional frontal teaching methods (learning-by-heart) are being mostly applied. One of the most common mistakes, made by the teachers, is to teach about democracy by praising it, but not supplying an opportunity to practice a democratic way of life. In consequence, it is easier for people to talk about democratic ideals rather than implement them in real, day-to-day life. Research done by Keasey reveals that adolescents have problem with listening and judging arguments, which oppose their own opinions. Such a situation is further the base for discussions in a democratic state, where everybody has his right to express his beliefs and opinions without being defamed or being a victim of violence. This implies that the moral competence is - in general - low and vulnerable to authoritarian pressures. We thus need to learn to judge moral arguments based on their moral quality and not whether they support or not my own beliefs. Adolescents who seek for solutions and make difficult decisions have a good opportunity to calm their negative emotions. In moral education, the teacher may not use his authority in order to impose his own beliefs on his students. Adolescents should have a possibility to discuss problems freely, without unnecessary interventions of the teacher. Georg Lind's Konstanz Method of Dilemma Discussion offers them such opportunities. 


\section{General scenario of a KMDD-session}

A KMDD-session goes as follows: The teacher commences the classes by reading aloud a story, which he believes to provoke the feeling of a dilemma. The story is then distributed in writing to all of the participants, who quietly re-read the story in order to fully understand the given problem. The teacher initiates an introductory reflection by asking whether the participants feel that there is a moral dilemma, and if so - why is it a dilemma. The participants are then asked to judge - by raising hands - whether they believe that a possible solution, given in the story, is right or wrong. Proponents and opponents then divide in small groups and try to collect as many arguments supporting their opinion, as possible. Then, the proper discussion between the two groups is initiated. It is based on two rules. The first one, called the rule of respect, demands that the participants share a feeling of mutual respect for each other, that is, say anything they want to say but not to make negative or positive comments about any people. The second rule, called the ping-pong rule, explains how the discussion is being led - when the speaker finishes his statement, he or she calls up a willing person from the opposing group, who will continue the debate. These two rules guarantee a just and efficient discussion. The arguments given by both sides are being noted on the blackboard during the discussion. After the debate, the participants are asked to look into the arguments given by the opposing side and decide which one of them is - in their own opinion - the best one. After this, the participants vote once again, whether they think that the hero of the story acted right or wrong.

The session described above was the first part of the KMDD SeminarWorkshop, led by Professor Lind. He believes that participation and experience are crucial in strengthening of personal moral-democratic competencies.

\section{Role of an educative moral dilemma story}

One of the crucial elements of the KMDD is the short story, which is the starting point of the debate. One of the aims of the workshop was to acknowledge the participants on the theoretical bases of constructing such a story. Furthermore, the workshop enabled the participants to develop their own educative moral dilemma story and polish it with the help of other participants.

It is particularly important to note that the moral dilemma does not actually reside in the story itself. It is rather being constructed by the reader. In consequence, one should know that while developing an educative moral dilemma, it is important to take into account other peoples feelings, opinions and moral orientations in order to make it possible for everyone to find an actual moral dilemma. It is obvious that, 
in such a case, it is impossible to construct an universally stimulating story consisting a moral dilemma. Cultural, linguistic, social upbringing - along with other factors - influence how listeners and readers perceive a given story. One story may provoke moral ambiguity in Western societies and - in the same time - be perceived by Latino societies as a clear and unequivocal situation which does not demand any special attention. Thus, is it clear that the teacher should try to decide and adapt the story to the sociocultural background of the participants.

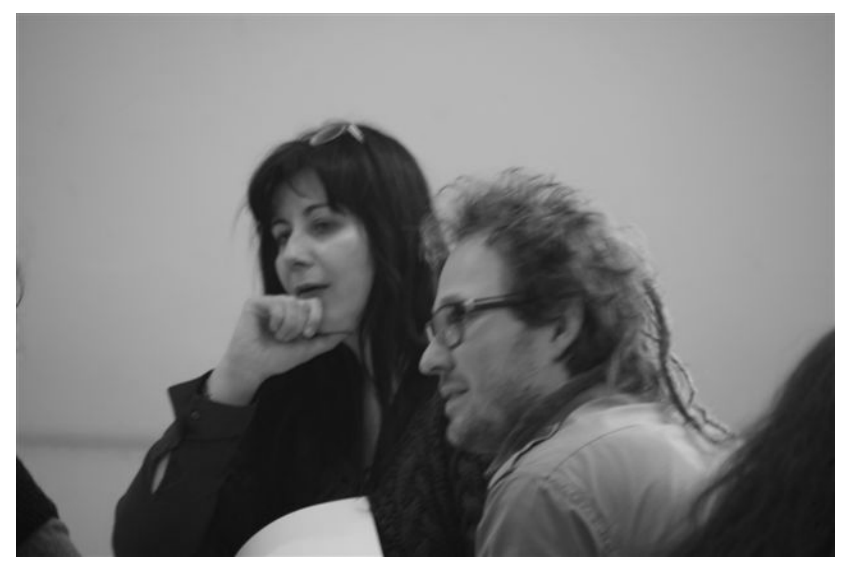

Everyone joins the discourse

It should also be noted that - basing on the Yerkes-Dodson Law - the given story should not provoke neither too much nor not enough emotional engagement. In both cases - when the emotions are too high or too low - the educative impact of the story is being lost; thus it is important to provoke and support emotional reactions, bearing in mind certain limitations.

The aforementioned suggestions on how to develop an educative moral dilemma have been broadened by Lind with a number of practical advices. It is important to create a clear main hero of the story, by giving him a name and facing him with a difficult and inevitable choice to make. The story should remain short and be expressed in informal casual language, so that everybody could understand it. Implementing the difficult choice in an everyday life routine helps the readers and listeners to identify with the problem on a personal level, thus enabling them to create an emotional engagement towards the given problem. The choice made by the main actor should be clear and visible in the story. Also, there should not exist any "technical" ways to evade the given choice. To sum up the advices given by Lind, it should be restated that it is the recipient of the story who "creates" the feeling of moral ambiguity and thus "imposing" the moral dilemma into the story. In consequence, the author should take into account possible moral perplexity of the 
participants, thus adapting the story in a way that maximises the number of participants, who will feel a moral dilemma in the story (Lind: 2009a).

Basing on the advices and suggestions proposed by Professor Georg Lind, the participants of the workshop prepared during two sessions of the workshop their own stories, provoking educative moral dilemmas. After confronting the primary versions of their stories with the recommendations of Professor Georg Lind, it became obvious how much work is needed in order to transform the first drafts of the stories into ones that could be used within the Konstanz Method of Dilemma Discussion. Thanks to the help and advices of both Lind and Nowak, along with the critical reception of the stories by other participants, it became possible to recreate the original stories into educative dilemmas.

During further sessions of the workshop, the participants have been introduced to the elementary rules on how to present a story, possessing an educative moral dilemma. The body language, along with a sentient way of speaking are the most important discussion points during this session. A speaking way which introduces micro-pauses enables the listeners to fully understand the recounted story and helps them identify the crucial issues of the story. Real-time practice shown how important such consciousness in dilemma presentation is; without them, the listeners shall remain overwhelmed by the information given in a short period of time, thus making it impossible to actually feel the existence of moral ambiguity. The participants also took turns in practising this capability; in groups of four people, in which two played the roles of students, one worked as a supervisor and finally one who re-enacted the figure of the teacher, reading aloud the story, putting into account their body language and proper way of speaking. Participants of such a training experienced how important it is to remain sentient of how we speak in order to foster the feeling of moral ambiguity in our listeners.

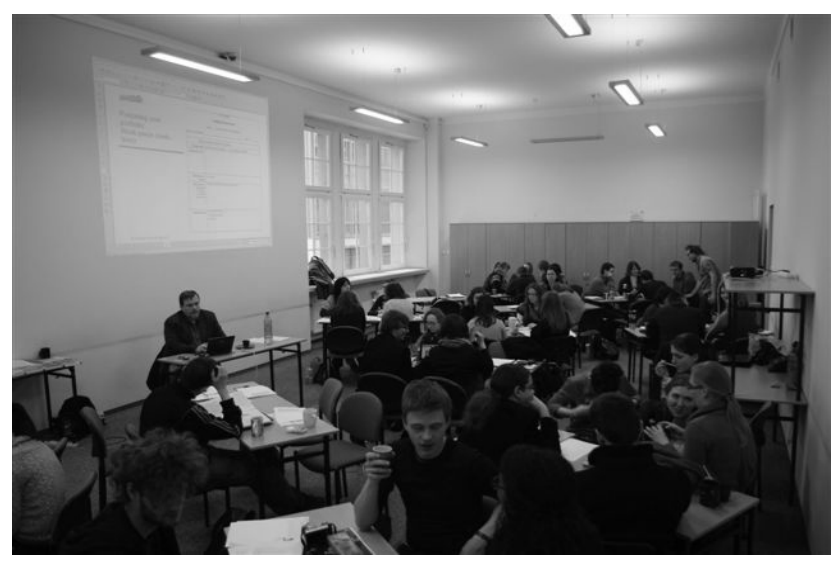

Thinking and acting together 


\section{Moral Judgement Test as the point of depart of the KMDD}

One of the important elements of the method of fostering democratic competences, developed by Georg Lind, is the Moral Judgement Test, which makes it possible to "assess the ability of people to judge arguments pro and con a controversial moral problem on the basis of their own moral principles, that is, irrespective of their opinion on the particular problem. Besides this, it should provide measures of the participants' attitudes toward the six Kohlbergian stages of moral reasoning" (Lind, 2008b, p. 195). The Moral Judgement Test uses the C-scale (" $\mathrm{C}$ " standing for Competence). The lowest possible value of the C-score is 0 , which indicates, that the participant failed to recognize the moral value of given arguments. The highest value of 100 indicates - in opposition - that the participant judged the given arguments only basing on their moral significance. The Moral Judgement Test makes it possible two aspects of democratic behaviour - both the cognitive competence and the moral orientation. The idea of the Test is thus to take into account the dual nature of fostering moral competences - as Lind stated, the cognitive and the affective dimensions are inseparable. The Moral Judgement Test confronts the tested group with two different stories, which are believed to provoke moral dilemmas. The task of the participants is to judge arguments for and against proposed solutions to the problem. The arguments reflect the six moral orientations by which Lawrence Kohlberg describes his six stages of moral development. In an ideal situation, the subject with high moral competence will reject arguments, which represent the low stages of moral development and accept arguments, which represent postconventional stages of moral development - regardless whether they support or not her or his own opinion on the problem. The given task stimulates both the affective dimension of moral reasoning (the task is to judge problems which may occur in daily life, and not only abstract concepts) and the cognitive dimension (participants are faced with both supporting and opposing justifications).

Lawrence Kohlberg divided his Six Stages of Moral Development into three main categories, which further divide into six stages: the pre-conventional phase, the conventional phase and the post-conventional phase. The pre-conventional phase is divided into two stages: the first is characterized by the will to avoid punishment and submission to authorities, the second on the other hand embraces acting in order to preserve one's own interests in an egoistic manner.

The first level of the conventional phase takes into account the existence of certain rules and norms of acting, thus promoting conformist behaviour. The second level concentrates on acknowledging certain authorities and whether those would accept or not possible ways of acting. On these levels, the personal motivation of behaviour is non-existent (Cern and Nowak, 2011, p. 396). 
Persons representing the post-conventional stage are described as being guided by their own beliefs and principles, along with their reference to the society. A person's action is guided by a sense of duty. On the first level, a person acknowledges and embraces democratic principles existing already in a given society.

On the highest level of moral development, according to Lawrence Kohlberg, ones actions are regulated by universal values and principles, such as justice, dignity, autonomy. A human being makes judgements, decisions and behaves accordingly to the Kantian categorical imperative (p. 398).

Lind's introduction into the Moral Judgement Test (MJT) was the basis for further practical exercises, which introduced the participants to the complexity and structure of calculating the C-score alongside with analysing and interpreting obtained data. Professor Georg Lind gave a clear emphasis on possible mistakes in both calculating and understanding the C-score. The MJT is an suitable instrument for evaluating the efficacy of KMDD-sessions and other method of moral education. "Although the competence score should not be upward fakeable, it should be sensitive to real changes over a wide range of the scale, either to upward changes, as a function of moral learning and intervention, or to downward changes, as a function of competence erosion", as said by Lind (Lind: 2008b, p. 193). Repeating the MJT in the group, with which classes based on the KMDD is being held, helps to evaluate whether the aim - fostering moral competences - is being achieved. If the teacher observes stagnation or regression of moral competence, it will compel him or her to think about improvements of his or her teaching.

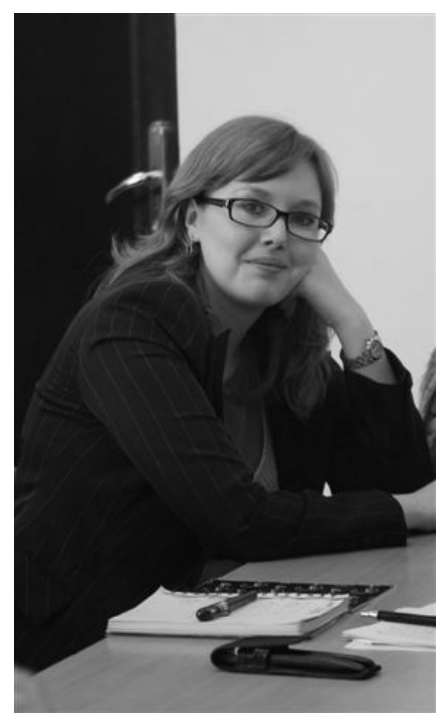

Listeners, thinkers, speakers 


\section{Influence of the KMDD on moral competence}

The conclusive moment of the workshop was to introduce the participants to possible influences of adapting KMDD methods in regular teaching. Basing on the data gathered by Lind, it becomes obvious how stimulating and beneficial in fostering democratic competences is using the KMDD. In general, Lind pointed out that in some education facilities an erosive trend of moral competence may be observed. Lack of possibilities to confront and freely discuss social controversies seems to have a strong impact on the regression of moral competence(Lind 2002). It is necessary to provide such opportunities in a regular manner in order to preserve and foster moral competence. Basing on his own experiences, backed with research findings, Lind demonstrated how a traditional lecture, lacking any kind of discursive intervention, fails to stimulate moral and democratic development and promotes stagnation. On the other hand, repeated interventions, based on the Konstanz Method of Dilemma Discussion, prove to have a stimulating effect on the students (Lind: 2009b). It is thus necessary to state that enabling students to participate in making decisions, taking responsibility and critical reflection are fundamental in high-quality education and teaching (Schillinger, 2006).

\section{KMDD fostering moral development}

Conclusions coming from the presentation by Lind informations on the Konstanz Method of Dilemma Discussion are - to say the least - encouraging. The fostering effect of KMDD-sessions are visible even with a limited number of interventions; only two KMDD-sessions per year can facilitate a moral competence development, however, the precondition is to be a well trained KMDD-teacher. Furthermore, the obtained results possess a long-lasting effect.

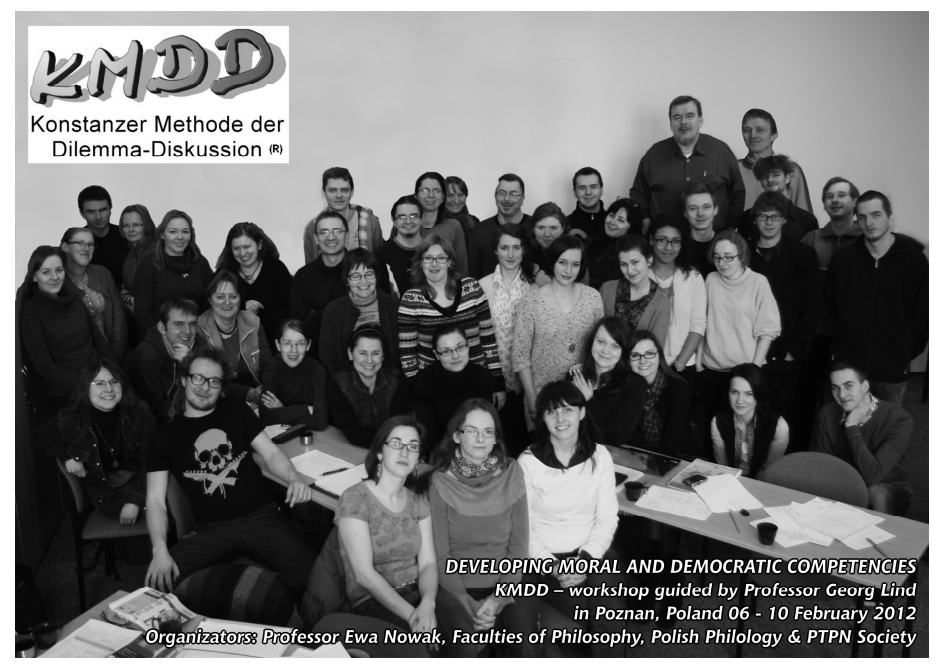

The group altogether 
To sum up the five-day workshop, the authors believe that the impact of Lind's method on the participants is difficult to overrate. Having the chance to confront one's ideas and methods of working with students with Georg Lind's knowledge and experience, along with personal participation in different tasks and exercises truly may be seen as fundamental for both future and present teachers of ethics, who wish to foster moral and democratic competence. Knowledge gained throughout the workshop, broadened by experience, is being represented in portfolios prepared during and after the workshop - which will prove to become useful learning and stimulating material for their authors. We wish to thank, on behalf of all the participants: Professor Georg Lind - for his kindness and openness during the workshop and his patience in explaining and mentoring his students; Professor Ewa Nowak - for her inspiring initiatives, aiming to enrich the Polish pedagogues and researchers by confronting them with innovative and worldrenown ideas and personalities.

\section{References}

Cern, K. M., Nowak, E. (2009, 2011). Ethos w życiu publicznym, Warsaw: PWN Publishing.

Lind, G. (2002). Ist Moral Lehrbar? Ergebnisse der modernen moralpsychologischen Forschung. Berlin: Logos-Verlag.

Lind, G. (2008a). Teaching students to speak ant to listen to others: Cultivating Moral Democratic Competencies. In: Doing Democracy and Social Justice in Education: Political Literacy for All Students, D.E. Lund \& P.R. Carr (eds.), New York: Peter Lang Publishing.

Lind, G. (2008b). The meaning and measurement of moral judgement competence. A dual-aspect model. In: Contemporary Philosophical and Psychological Perspectives on Moral Development and Education, Daniel Fasko Jr., Wayne Willis (Eds.), Creskill: Hampton Press.

Lind, G. (2009a). Checklist for Educative Moral Dilemmas. In: G. Lind, Moral ist Lehrbar, München: Oldenbourg.

Lind, G. (2009b). Favourable learning environments for moral development - A multiple intervention study with nearly 3.000 students in a higher education context, San Diego (congress-lecture). 
150 | Marta Szopka \& Filip Bardziński

Schillinger, M. M. (2006). Learning environment and moral development: How university education fosters moral judgment competence in Brazil and two German-speaking countries, Aachen: Shaker-Verlag. 